\title{
Penile fracture with bilateral corporeal rupture without urethral involvement
}

\author{
Tarik Yonguc, MD; ; Ibrahim Halil Bozkurt, MD;" Bumin Ors, MD;" Zafer Kozacıoglu, MD;" Burak Arslan, MD;* \\ Nilufer Goksin Yonguc, $M D^{+}$
}

*Izmir Bozyaka Research and Training Hospital Department of Urology, Izmir, Turkey; †'zmir University Faculty of Medicine Department of Anatomy, Izmir, Turkey

Cite as: Can Urol Assoc J 2014;8(1-2):e51-3. http://dx.doi.org/10.5489/cuaj.1226

Published online January 14, 2014.

\section{Abstract}

Concomitant urethral injury is rare in penile fracture. We report the case of a 34-year-old male who presented to the emergency department 12 hours after a blunt self-injury of the penis. Physical examination revealed a swollen, ecchymotic, and deviated circumcised penis without blood at the meatus. The fracture line extending along the bilateral corpora without urethral involvement was seen intraoperatively. The fracture side was repaired primarily. The patient healed and recovered without complication. To our knowledge, this is the second reported case of bilateral corporeal rupture without urethral involvement.

$P$ enile fracture is characterized by corpus cavernosal rupture, resulting from sudden bending or pressure on the penis during an erection. This is an uncommon, but emergent urological condition. ${ }^{1}$ Associated urethral injuries are reported in $1 \%$ to $38 \%$ of patients. ${ }^{2}$ In cases with bilateral cavernosal rupture, urethral injury should be suspected. ${ }^{3}$ We report a rare case of a penile fracture with bilateral corporeal rupture without urethral involment. To our knowledge, this is the second reported case.

\section{Case report}

We report the case of a 34-year-old male who presented to the emergency department 12 hours after a blunt selfinjury of the penis. The patient had been doing taghaandan (cracking the penis) for about 15 years; this time, however, he felt a tearing/popping sensation, and reported rapid detumescence and severe penile pain, but he has been able to void well. Physical examination revealed swollen, ecchymotic, and deviated circumcised penis without blood at the meatus (Fig. 1). Appropriate concern for penile fracture led to operative management. At the time of the operation, after urethral catheterization, a subcoronal circumcising incision was made and the penis was degloved. No local debridement or any vessel ligation was required. After evacuating a large hematoma, we found a significant defect in the ventral side of the left corpus cavernosum (Fig. 2). With further dissection, we found that the defect extended along both corpus cavernosum, posterior to urethra. The urethra was elevated after sharp and blunt dissections and was intact. The defects were repaired with 3-0 PDS in simple running fashion sutures. An intraoperative artificial erection was induced with saline to confirm water-tight closure of the tunica and the absence of any other tears or deformities. The subcoronal incision was repaired with 3-0 rapid-vicryl with simple interrupted sutures. The urethral catheter was removed on postoperative day 1 and the patient was discharged without any complication. He had satisfactory painless erections without penile curvature and an International Index of Erectile Function (IIEF) score of 23 at the 3-month follow-up visit. Moreover, he could void spontaneously without difficulty.

\section{Discussion}

In the Middle East, a common cause of penile fracture is selfinflicted injury. ${ }^{4}$ This practice of taghaandan occurs when the erect penis is bent or struck to achieve rapid detumescence. ${ }^{4}$ The increased risk of penile rupture during tumescence is partially due to the fact that the tunica albuginea stretches and thins when the penis is erect. Studies show that the tunica albuginea, when the penis is in a flaccid state, it is up to $2.4 \mathrm{~mm}$ thick; when the penis is erect state, the tunica albuginea can be as thin as 0.25 to $0.5 \mathrm{~mm} .{ }^{5}$ In addition to this change in thickness, traumatic penile rupture may be associated with histologic changes in the tunica albuginea rendering it more prone to fracture. Evidence of 


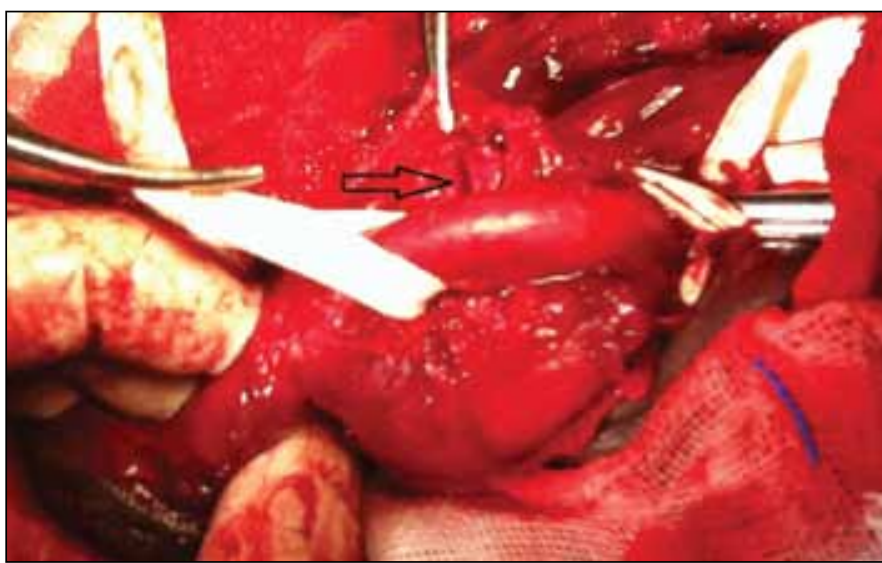

Fig. 1. Fracture site; the urethra has been elevated.

fibrosclerosis and cellular infiltrates has been documented on pathologic review of ruptured tunica albuginea. These changes can be due to previous trauma, which could predispose the tunica albuginea to rupture at lower pressures. ${ }^{6}$

The laceration is often unilateral, though bilateral rupture accounts for $2 \%$ to $10 \%$ of cases. ${ }^{7}$ Zargooshi reported 251 penile fractures in which the tear was right-sided in 163 cases, left-sided in 86 and bicorporeal in only $2 .^{8}$ Concomitant urethral injury is rare, with reported frequencies in the $9 \%$ to $20 \%$ range. ${ }^{3,9}$ Patients with bilateral corporeal rupture should be assumed to have urethral injury. ${ }^{9}$ Srinivas and colleagues reported a unique case with bilateral rupture of the crura of the cavernosa without urethral injury..$^{10}$ After this case, our case, to the best of our knowledge, is the second one reporting bilateral corporeal rupture without urethral involvement.

Compared with penile fractures during sexual intercourse, it is likely that taghaandan injuries have less risk of synchronous urethral rupture. The reason may be attributed to the lack of additional opposed force provided by the partner's body weight; the entire load of the thrust done by the patient himself.

Blood at the meatus, an inability to void, or hematuria are signs of urethral injury. Urethral bleeding without urethral injury has been reported after penile fracture. ${ }^{11}$ False negative results have been reported with retrograde urethrography; therefore, some patients and surgeons prefer early surgery and direct inspection of urethra regardless of negative uretrography. ${ }^{12,13}$ This is our practice. The fracture site is close to the urethral rupture and can be diagnosed and repaired easily intraoperatively. ${ }^{14}$

Regarding the corporal injury, studies have shown that immediate surgical repair is vital and leads to better outcomes and less complication when compared to non-operative management. Bennani and colleagues reported complication rates of $40.7 \%$ and $8.2 \%$ for conservative treatment and surgery, respectively. ${ }^{15}$

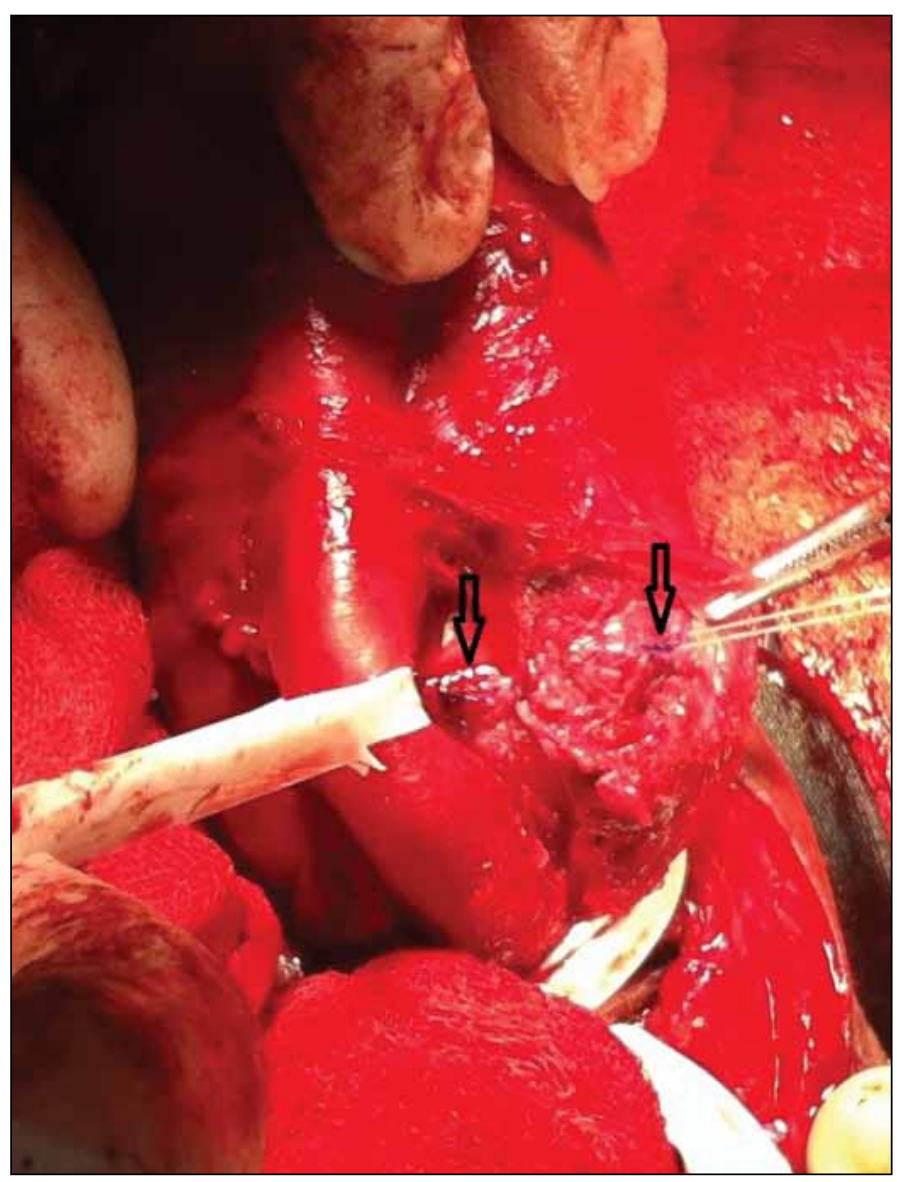

Fig. 2. The bilateral fracture line extending posterior to urethra; the urethra is intact.

In our case, the patient was operated as soon as possible after his arrival at our clinic but about 12 hours after the blunt injury had occured. Kozacıoglu and colleagues published a series of 43 patients sorted into 3 groups according to the time interval until surgery. As a result, there were no significant differences between these groups. Neither serious deformities nor erectile dysfunction occurred in the longterm as a result of a delay in surgery within a given period of time in cases with no urethral involvement. ${ }^{14}$ In our case a delay of 12 hours at admission did not cause any curvature or erectile dysfunction.

Competing interests: Dr. Yonguc, Dr. Bozkurt, Dr. Ors, Dr. Kozacioglu, Dr. Arslan and Dr. Yongucm all declare no competing financial or personal interests.

This paper has been peer-reviewed. 


\section{References}

1. Farah RN, Stiles Jr R, Cerny JC. Surgical treatment of deformity and coital difficulty in healed traumatic rupture of the corpora cavernosa. J Urol 1978;120:118-20.

2. Fergany AF, Angermeier KW, Montague DK. Review of cleveland clinic experience with penile fracture. Urology 1999;54:352-5. http://dx.doi.org/10.1016/S0090-4295(99)00115-6

3. Ibrahiem el-HI, el-Tholoth HS, Mohsen T, et al. Penile fracture: Long-term outcome of immediate surgical intervention. Urology 2010;75:108-11. http://dx.doi.org/10.1016/j.urology.2009.08.057

4. Zargooshi J. Penile fracture in Kermanshah, Iran: Report of 172 cases. J Urol 2000; 164:364-6. http:// dx.doi.org/10.1016/S0022-5347(05)67361-2

5. Bitsch M, Kromann-Andersen B, Schou J, et al. The elasticity and the tensile strength of tunica albuginea of the corpora cavernosa. J Urol 1990;143:642-5.

6. De Rose AF, Giglio M, Carmignani G. Traumatic rupture of the corpora cavernosa: New physiopathologic acquisitions. Urology 2001;57:319-22. http://dx.doi.org/10.1016/S0090-4295(00)00926-2

7. Dever DP, Saraf PG, Catanese RP, et al. Penile fracture: Operative management and cavernosography. Urology 1983;22:394-6. http://dx.doi.org/10.1016/0090-4295(83)90418-1

8. Zargooshi J. Sexual function and tunica albuginea wound healing following penile fracture: An 18-year follow-up study of 352 patients from Kermanshah, Iran. J Sex Med 2009;6:1141-50. http://dx.doi. org/10.1111/i.1743-6109.2008.01117.x
9. Tsang T, Demby AM. Penile fracture with urethral injury. J Urol 1992; 147:466.

10. Srinavas BV, Vasan SS, Mohammed S. A case of penile fracture at the crura of the penis without urethral involvement: Rare entity. Indian I Urol 2012;28:335-7. http://dx.doi.org/10.4103/09701591.102718

11. Asgari MA, Hosseini SY, Safarinejad MR, et al. Penile fractures: Evaluation, therapeutic approaches and long-term results. J Urol 1996;155:148-9. http://dx.doi.org/10.1016/S0022-5347(01)66578-9

12. Mydlo JH, Hayyeri M, Macchia RJ. Urethrography and cavernosography imaging in a small series of penile fractures: A comparison with surgical findings. Urology 1998;51:616-9. http://dx.doi.org/10.1016/ S0090-4295(97)00701-2

13. Beysel $M$, Tekin $A$, Gurdal $M$, et al. Evaluation and treatment of penile fractures: Accuracy of clinical diagnosis and the value of corpus cavernosography. Urology 2002;60:492. http://dx.doi.org/10.1016/ S0090-4295(02)01813-7

14. Kozacioglu $Z$, Degirmenci $T$, Arslan $M$, et al. Long-term significance of the number of hours until surgical repair of penile fractures. Urol Int 2011;87:75-9. http://dx.doi.org/10.1159/000325589

15. Bennani $S$, El-Mrini $M$, Meziane F, et al. Traumatic rupture of the corpus cavernosum: 25 case reports and literature review [in French]. Ann Urol (Paris) 1992;26:355.

Correspondence: Dr. Tarik Yonguc, Izmir Bozyaka Research and Training Hospital Department of Urology, Izmir, Turkey; tyonguc@gmail.com 